\title{
Surgical Aspects of Ovarian Tissue Removal and Ovarian Tissue Transplantation for Fertility Preservation
}

\author{
Operative Aspekte der Ovargewebsentnahme und Ovargewebstransplantation \\ zur Fertilitätsprotektion
}

Authors

Affiliation
M. W. Beckmann, R. Dittrich, S. Findeklee, L. Lotz

Frauenklinik, Comprehensive Cancer Center ER-EMN, Universitätsklinikum Erlangen, Friedrich-Alexander-Universität Erlangen-Nürnberg, Erlangen, Germany

\author{
Key words \\ - surgical techniques \\ ovarian tissue \\ - fertility protection in cancer \\ - fertility preserving \\ techniques \\ - oncofertility \\ Schlüsselwörter \\ - operative Technik \\ - Ovargewebe \\ - Fertilitätsprotektion bei \\ Krebserkrankung \\ - fertilitätserhaltende \\ Techniken \\ - Onkofertilität
}

Deutsche Version unter: http://dx.doi.org/ $10.1055 / \mathrm{s}-0042-115017$

$\begin{array}{ll}\text { received } & 4.7 .2016 \\ \text { revised } & 7.8 .2016 \\ \text { accepted } & 8.8 .2016\end{array}$

Bibliography

Dol http://dx.doi.org/ 10.1055/s-0042-115017 Geburtsh Frauenheilk 2016; 76 : 1057-1064 @ Georg Thieme Verlag KG Stuttgart · New York ISSN 0016-5751

\section{Correspondence}

Prof. Matthias W. Beckmann Frauenklinik

Comprehensive Cancer Center ER-EMN

Universitätsklinikum Erlangen Friedrich-Alexander-Universität Erlangen-Nürnberg Universitätsstraße 21 91054 Erlangen

Germany

fk-direktion@uk-erlangen.de

\section{Abstract \\ $\nabla$}

Introduction: The removal of ovarian tissue prior to starting oncologic treatment and the subsequent transplantation of this tissue after completing therapy have become increasingly important surgical fertility-preserving techniques. The aim of this review was to investigate the different surgical techniques used for this method reported in the literature to date and to discuss the advantages and disadvantages of the respective techniques.

Review: A search was done in MEDLINE using a defined algorithm to find studies published between January 2004 and December 2015. All study designs were included in our review if they contained statements on the surgical technique used. We found 16 publications ( 8 retrospective cohort studies, 6 case reports and 2 systematic reviews) with a total of 1898 female patients which reported on the surgical technique used for ovarian biopsy and 15 publications (7 retrospective cohort studies, 6 case reports and 2 systematic reviews) with a total of 455 women which mentioned the surgical technique used for ovarian transplantation. Different surgical techniques can be used both for ovarian biopsy and for the transplantation of ovarian tissue. A number of different surgical routes have been used, and the amount of tissue extracted, the instruments used, the treatment of the ovary, the transplantation site, the blood supply to the transplanted ovarian tissue and the procedure used for simultaneous surgical interventions vary.

Conclusion: In future, one of the tasks will be to establish a standard surgical method for ovarian extraction and transplantation which will have a low rate of complications and a high pregnancy and birth rate while ensuring that the transplanted tissue is fully functional.

\section{Zusammenfassung \\ $\nabla$}

Einleitung: Die Entnahme von Ovargewebe vor Beginn einer onkologischen Therapie und seine Transplantation nach Abschluss der Therapie sind operative fertilitätsprotektive Techniken mit stetig zunehmendem Stellenwert. Ziel dieses Reviews ist es, die verschiedenen operativen Techniken bei diesem Verfahren auf Grundlage der bisher veröffentlichten Literatur zu analysieren und ihre Vor- und Nachteile zu diskutieren.

Review: Zwischen Januar 2004 und Dezember 2015 publizierte relevante Studien wurden auf MEDLINE nach einem definierten Algorithmus gesucht. Es wurden alle Studiendesigns eingeschlossen, sofern eine Aussage zur operativen Technik getroffen wurde. Wir fanden 16 Publikationen ( 8 retrospektive Kohortenstudien, 6 Fallberichte und 2 systematische Reviews) mit insgesamt 1898 Patientinnen, in denen auf die operative Technik bei der Ovargewebsentnahme eingegangen wurde, und 15 Veröffentlichungen (7 retrospektive Kohortenstudien, 6 Fallberichte und 2 systematische Reviews) mit 455 Frauen, die sich mit der operativen Technik bei der Ovartransplantation beschäftigten. Es existieren verschiedene operative Techniken sowohl für die Entnahme als auch die Transplantation von Ovargewebe. So existieren verschiedene operative $\mathrm{Zu}$ gänge sowie Variationen bei der Menge des extrahierten Gewebes, den verwendeten Instrumenten, der Versorgung des Ovars, der Lokalisation und Versorgung des Transplantats und bei der Durchführung simultaner operativer Eingriffe.

Schlussfolgerungen: Eine zukünftige Aufgabe wird es sein, für die Ovarentnahme und -transplantation eine standardisierte Operationsmethode zu etablieren, die mit einer niedrigen Komplikationsrate sowie einer hohen Schwangerschafts- und Geburtenrate bei guter Funktionalität des Transplantats einhergeht. 


\section{Introduction}

$\nabla$

The oncological successes in recent years and decades have led to new medical challenges. Newly available systemic therapies have significantly increased long-term survival rates, particularly of patients with hematologic neoplasms. The 10-year survival rates of women with leukemia or lymphoma has risen to $90 \%$. But the anti-carcinogenic impact of systemic therapies has been at the expense of diminishing ovarian reserve. It has not yet been possible to reduce the gonadotoxic effect of chemotherapeutic agents $[1,2]$. Many young women newly diagnosed with cancer would like to have children at some point in the future. Surveys of women with cancer have shown that almost one in seven women with disease would even be prepared to accept poorer long-term oncologic outcomes if this meant that they would be able to have children at some stage in the future [3]. Particularly in the last decade, a number of methods for fertility protection have been developed which take these needs into account.

The classic approach, which is also the oldest one, consists of administering a GnRH analog to suppress gonadal function, starting 1-2 weeks prior to chemotherapy and continuing up to 2 weeks after concluding chemotherapy. But the American Society for Reproductive Medicine is of the opinion that this fertility-protecting method is insufficient in itself [4]. A number of studies have reported a potential benefit following therapy with GnRH analogs. One of these studies was the recently completed OPTION trial [5]. However, the number of patients in the groups was small, meaning that the data are still insufficient to permit any general recommendations to be made regarding the benefits of this group of drugs for fertility protection. In contrast to other fertility protecting methods, the administration of a GnRH analog is not a standard approach for fertility protection. The use of drugs to suppress gonadal function is particularly controversial in women with hormone receptor-positive breast cancer because of concerns that the tumor will subsequently be less sensitive to adjuvant endocrine therapy. In patients scheduled to undergo pelvic radiotherapy in addition to or instead of chemotherapy, one option is to relocate the ovaries outside the area requiring irradiation or to cover them prior to radiotherapy. In the literature this option has a $70 \%$ chance of preserving ovarian function [6]. The technique of ovarian hormonal stimulation followed by follicle puncture with cryopreservation of unfertilized or fertilized oocytes was developed in the 1990s. In principle, this method can be carried out in all cycle phases [7]. The advantage of this approach is that it avoids abdominal surgery. Limitations of this fertility-protecting method include the delay in starting oncologic treatment and reservations with respect to hormone-sensitive tumors. This method can therefore usually not be used in patients with highly proliferative malignances such as hematologic neoplasms. There are no indications to date that stimulation with gonadotropins to obtain oocytes results in a poorer prognosis in patients with hormone receptor-positive breast cancer. Nevertheless, numerous patients have expressed their anxiety and opted against this method of fertility protection. The most recent and most innovative fertility protection method used in women with cancer consists of cryopreservation of part of the ovary, which is removed prior to starting oncologic therapy and subsequently transplanted back after concluding treatment. Ovarian cryopreservation as a means of protecting the fertility of cancer patients is a method that has evolved rapidly in the last decade. It is now considered a standard fertility-preserving approach and, following its increasing success, has lost its previously ex- perimental character. Which method should be used for fertility protection in the respective situation depends on the type, duration and intensity of the planned oncologic therapy [8]. A combination of several or even all methods of fertility protection is also possible. There is much to be said for ovarian cryopreservation with the tissue stored in an ovarian cryo-bank, followed by transplantation of the tissue at a later date. The most important argument in favor of this fertility-preserving method has to be the lack of delay between the fertility-preserving procedure and the start of oncologic therapy. It is the only fertility preservation option available to prepubertal girls with cancer, the only method which can restore patients' fertility after a loss of fertility and the only method which even offers the possibility of conceiving naturally. After Donnez et al. reported in 2004 on the first pregnancy achieved following the transplantation of ovarian tissue extracted prior to the start of cancer therapy, around 75 children have been born worldwide with the help of this method [9]. However, this method is a surgical procedure. Despite the fact that this method is now in widespread use, with the exception of a few published case series from individual centers there are still no overviews which have considered the surgical techniques required for this method and their advantages and disadvantages. The aim of this review was therefore to analyze the accounts published by different centers on the extraction of ovarian tissue and the subsequent re-transplantation of this tissue with respect to the different surgical techniques used and to discuss the advantages and disadvantages of the respective techniques.

\section{Review}

$\nabla$

This paper is a systematic review of the published literature on the surgical techniques used to extract and transplant ovarian tissue to preserve the fertility of women with cancer. A search was done in MEDLINE for relevant publications published between January 2004 and December 2015. The search terms were "removal of ovarian tissue", "extraction of ovarian tissue", "surgical techniques", "complications", "transplantation of ovarian tissue”, "fertility preservation" and "ovarian surgery". The search was limited to the extraction and transplantation of ovarian tissue in humans. There were no restrictions placed on the search with respect to the language of publication. Publications in English, French and German were all included in the review. The references included in the selected publications were also taken into account in the hope of finding additional articles. The titles and abstracts of potentially relevant articles were read to find out whether they met the desired criteria. The data from the relevant articles was transferred to a data form which had been developed and tested previously by our Review group.

The following criteria were considered when analyzing the surgical technique:

\section{For the extraction of ovarian tissue:}

- The surgical approach used to extract ovarian tissue

- The amount of ovarian tissue extracted during the procedure

- The instruments used during tissue extraction

- The treatment of the surface of the ovary after tissue extraction

- Whether another surgical procedure was carried out simultaneously during the extraction of ovarian tissue

For the transplantation of ovarian tissue:

- The surgical approach used to transplant ovarian tissue

- The transplantation site

- The instruments used for ovarian tissue transplantation 


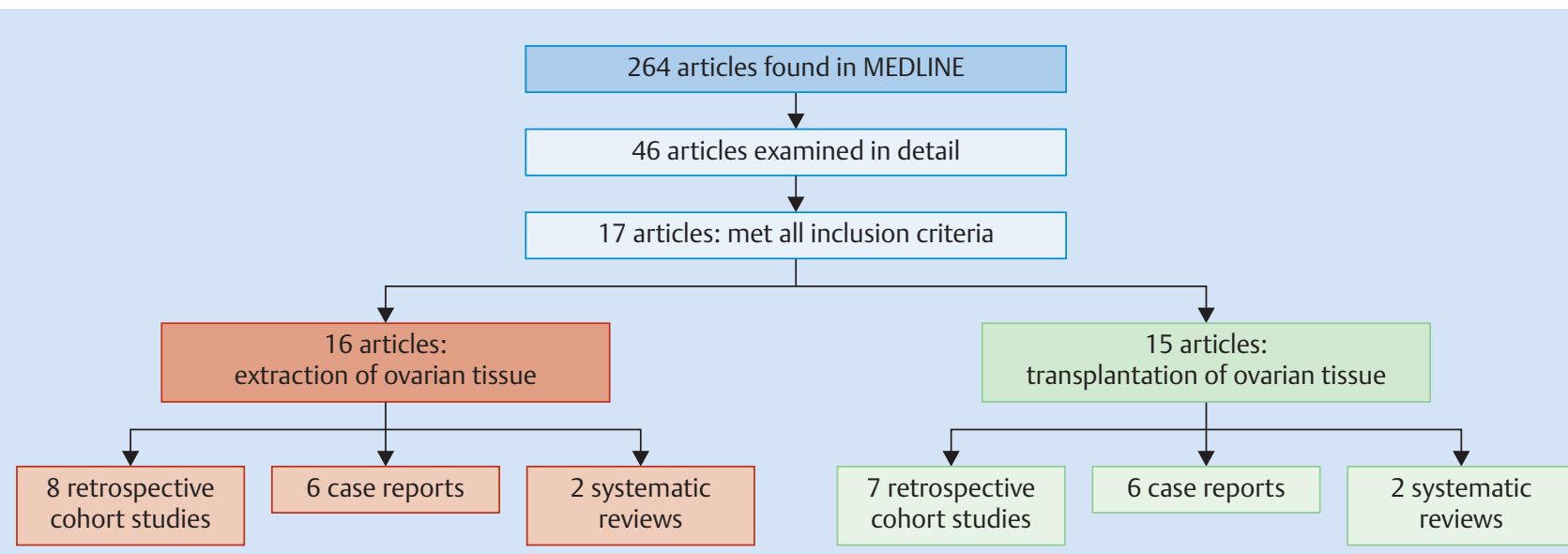

Fig. 1 Flow diagram of the literature search process.

- The surgical treatment of the transplantation site

- Whether other surgical procedures were carried out simultaneously during transplantation

The MEDLINE search using the search algorithm described above in Materials and Method resulted in 264 publications. After screening the titles and abstracts of the articles, the full texts of 46 articles were reviewed in more detail. A total of 17 articles met all 3 inclusion criteria (description of the surgical technique used to extract ovarian tissue and/or used in ovarian tissue transplantation to protect the fertility of women with cancer treated between 2004 and 2015).

16 articles reported on the extraction of ovarian tissue. Eight of these publications were retrospective cohort studies, 6 were case reports, and 2 consisted of systematic reviews. Three of the publications only reported on the extraction of ovarian tissue, irrespective of any transplantation procedures carried out at a later date.

A total of 15 articles included information on the surgical technique used for ovarian tissue transplantation ( 7 retrospective cohort studies, 6 case reports, and 2 systematic reviews). One article dealt only with the transplantation of ovarian tissue without any mention of the previous extraction of ovarian tissue [10-26]. - Fig. 1 shows the process of the literature search.

The data obtained covered for the extraction of ovarian tissue in 1898 women. The most common indication for this fertility-preserving technique was breast cancer ( $n=832,43.8 \%$ ), followed by hematologic neoplasm ( $n=785,41.4 \%$ ). There was no information available on the diagnosis of 16 patients ( $0.8 \%)$. The mean age at the time of ovarian tissue extraction was 26.5 years (range: 0.5-39.8 years). Two studies provided no information on patient age. Data on the transplantation of ovarian tissue was available for 455 women. As with the group of patients who underwent ovarian tissue extraction, the most common diagnoses of women undergoing ovarian tissue transplantation were breast cancer ( $n=169,37.1 \%)$ and hematologic malignancy $(n=147,32.3 \%)$. Three articles reporting on a total of 23 patients (5.1\%) provided no information on the diagnosis. Fig. 2 shows the oncologic diagnoses of women whose ovarian tissue was cryopreserved. The average age at the time of ovarian tissue extraction was 27 years. The interval between extraction and transplantation was 2-8 years. Four articles did not provide information on patient age at the time of transplantation.

\section{Surgical technique}

Surgical route used for the extraction of ovarian tissue Most authors used a laparoscopic approach to extract ovarian tissue. Only Rosendahl et al. and Silber et al. reported on the use of mini-laparotomy procedures to extract ovarian tissue in children. The mini-laparotomy was carried out by an experienced pediatric surgeon $[22,23]$.

\section{Amount of extracted ovarian tissue}

Most centers opted to remove $1 / 3$ (254 women) or $2 / 3$ of the ovary (446 women). Schmidt et al., Demeestere et al. and Revel et al. removed an entire ovary in a total of 104 women [16,18,19]. Donnez et al. and Silber et al. only took biopsies of ovarian tissue with a maximum diameter of $<2 \mathrm{~mm}$ from a total of 77 women. The other articles (1017 women) provided no information on the amount of tissue sampled. In their review of 60 ovarian extractions and transplantations performed in 3 different centers, Donnez et al. reported that biopsies of ovarian cortex needed to have a thickness of at least $1-1.5 \mathrm{~mm}$ because primordial follicles are present at a depth of approximately $0.8 \mathrm{~mm}$ from the mesothelium [11]. With superficial or thin biopsies there is a risk that no primordial follicles will be included in the sampled tissue, preventing the creation of any fertility reserve. This risk can be prevented by removing part of the ovary for cryopreservation. In contrast to previous assumptions, it is enough to extract and preserve only part of an ovary. 0 Fig. 3 shows a partially extracted ovary.

\section{Instruments used for extraction}

The standard procedure for extracting ovarian tissue for fertility protection uses scissors or scalpels without coagulation. Dittrich et al., Huober-Zeeb et al. and Lawrenz et al. reported on the use of this surgical technique in fertility-preserving procedures carried out in 560 women $[10,12,21]$. Silber et al. used microbipolar biopsy forceps to ensure sufficient hemostasis [23]. Other working groups preferred to use instruments without coagulation to minimize the surgical trauma to the sensitive ovarian tissue [12,21]. Rosendahl et al. pointed out that the use of electrical current intraoperatively can lead to a loss of primordial follicles. They recommended that bipolar coagulation of the ovarian surface should only be carried out after the sample of ovarian tissue had been 


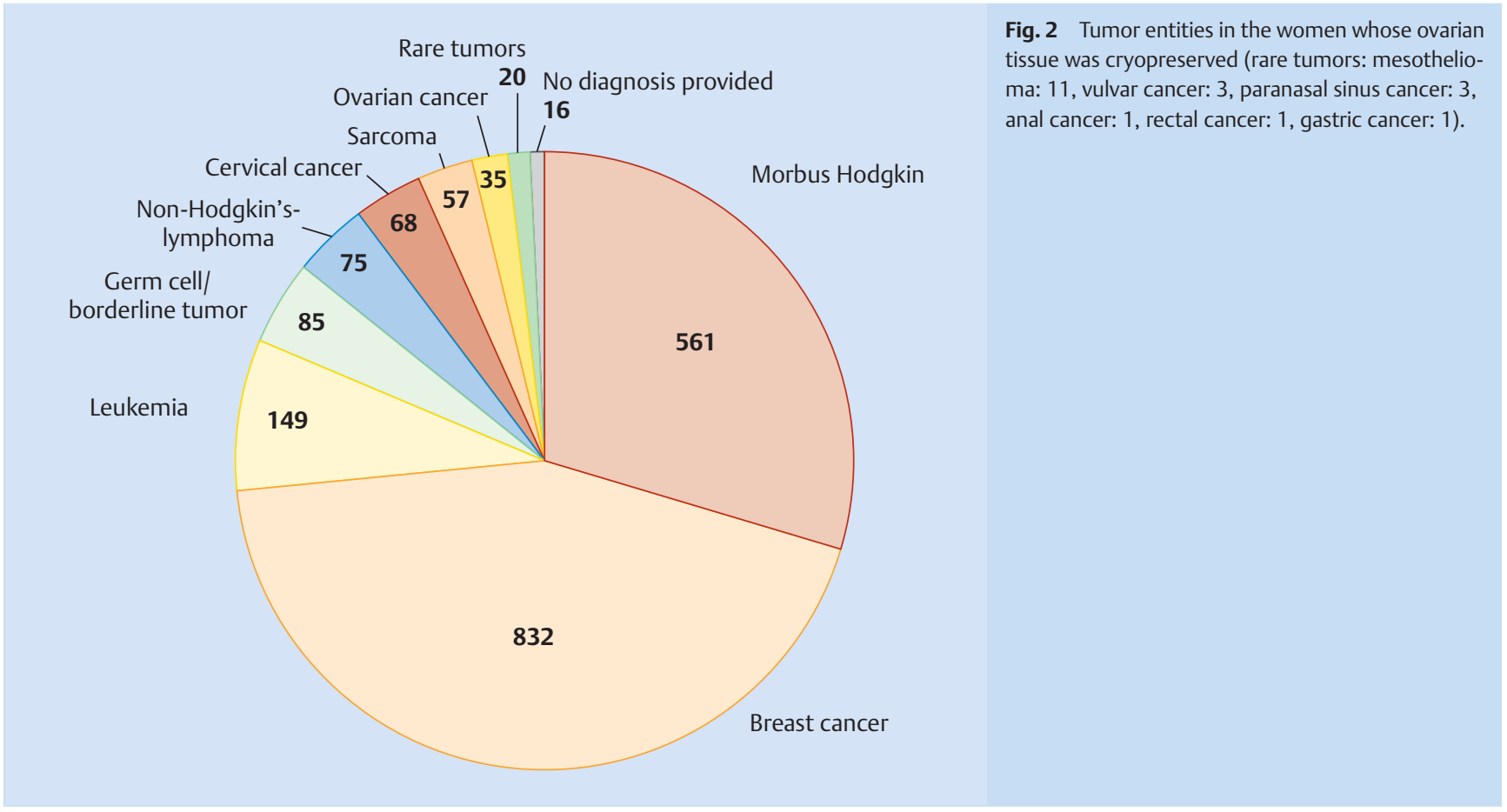

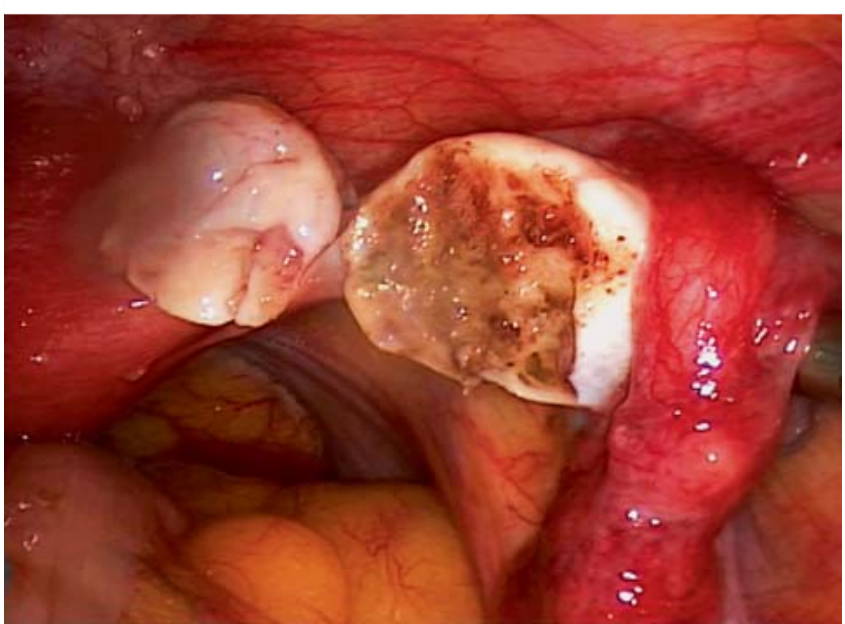

Fig. 3 Laparoscopic extraction of ovarian tissue. Left: partially extracted ovary; right: remnant of the remaining ovary; the surface has been treated with bipolar coagulation to achieve hemostasis.

removed and that coagulation should be done sparingly to protect the ovarian remnant [22].

\section{Treatment of the ovarian surface after extraction}

Based on 386 extractions of ovarian tissue carried out in their center, Rosendahl et al. recommended carrying out bipolar coagulation of the surface of the ovary after extracting the tissue segment for later transplantation if bleeding occurred on the surface of the ovary [22]. Silber et al. primarily used bipolar instruments, while Dittrich et al. only occasionally used bipolar current for coagulation in the first 20 extractions and transplantations of ovarian tissue carried out in their center [10,23]. Silber et al. proposed using fibrin glue or heparin saline solution to treat the surface of the ovary after tissue extraction, while Dittrich et al. did not treat the surface of the extracted ovarian sample $[10,23]$. The other working groups did not comment on the approach they used to treat the ovarian surface.

\section{Surgical procedures carried out simultaneously during extraction}

Other surgical procedures carried out simultaneously during ovarian tissue extraction for fertility preservation included the removal of myomas or adhesions and chromotubation. Dittrich et al. carried out myoma enucleation in one patient, and Revelli et al. described a patient who underwent chromotubation with methylene blue $[10,20]$. There were no other reports on simultaneous procedures in the literature.

An overview of published surgical techniques used for the extraction of ovarian tissue is given in $\$$ Table 1 .

\section{Surgical approach used to transplant ovarian tissue}

Most authors also opted for a laparoscopic approach when transplanting the ovarian tissue. Laparoscopy was done in 329 women; 2 women had a laparotomy and 2 girls underwent a combination of laparoscopy and laparotomy.

\section{Transplantation site}

The most common transplantation techniques used for grafting the ovarian tissue after completing oncologic therapy were transplantation of the tissue into a pelvic peritoneal pocket near the ovary and transplantation into the ipsilateral and/or contralateral ovary. 13 working groups who carried out ovarian transplantations in a total of 345 patients reported that transplantation was done into a peritoneal pocket. In 12 centers who carried out transplantations in a total of 351 women after cancer treatment, the transplantation site was the ovary. Imbert et al., Donnez et al. and Dittrich et al. reported that transplantations were done both into a pelvic pocket and into the ovary in their respective centers. At the center of Dittrich et al., 16 women received an ovarian tissue transplant into the pelvic wall and 4 women underwent 
transplantation into both the pelvic wall and the ovary. Imbert et al. and Donnez et al. gave no breakdown of their figures $[10,11$, 26]. The physiology of the anatomical site along with the good supply of blood to the site and the ease of detection have all been cited as arguments in favor of transplantation into the ipsilateral and/or contralateral ovary [11]. In contrast, Dolmans et al. reported vascular growth into the transplanted specimen after grafting into the pelvic wall [24]. Transplantation into a peritoneal pocket offers the opportunity to carry out simultaneous transplantation immediately after preparation of the peritoneum or secondary transplantation in a second surgical procedure. Ten centers carried out simultaneous transplantation. Four centers opted for secondary transplantation at a later date; Imbert et al. carried out both primary and secondary transplantation into the peritoneum. The first ovarian transplantations tended to be carried out as a secondary surgical procedures as it was thought that tissue transplantation at a later stage would improve the supply of blood to the area [17]. Another transplantation technique used in 4 centers - although 2 centers did not exclusively use the technique - is heterotopic transplantation into subcutaneous fat tissue outside the pelvis $[16,18,22,26]$. O Fig. 4 shows a transplantation site in the right pelvic wall.

\section{Instruments used during transplantation}

Scissors without coagulation were used to prepare the transplantation site in the pelvic wall or ovary in procedures in 20 patients carried out at the center of Dittrich et al. [10]. Silber et al. used microbipolar forceps in 16 women [23]. While the main focus of Dittrich et al. was to protect ovarian tissue, Silber et al. focused more on preventing secondary bleeding. The other centers provided no information on the instruments they used.

\section{Surgical treatment of the transplantation site}

It is important to differentiate between transplantation to the ovary or into the peritoneum. For ovarian transplantation, Silber et al. recommended preparing the ipsilateral ovary up to the medulla. The ovarian tissue was cut into $0.8-1 \mathrm{~mm}$ thin strips which were sutured to the medulla of the ipsilateral ovary using 9-0 interrupted nylon sutures. The authors were of the opinion that this prevented hematoma formation under the grafted tissue

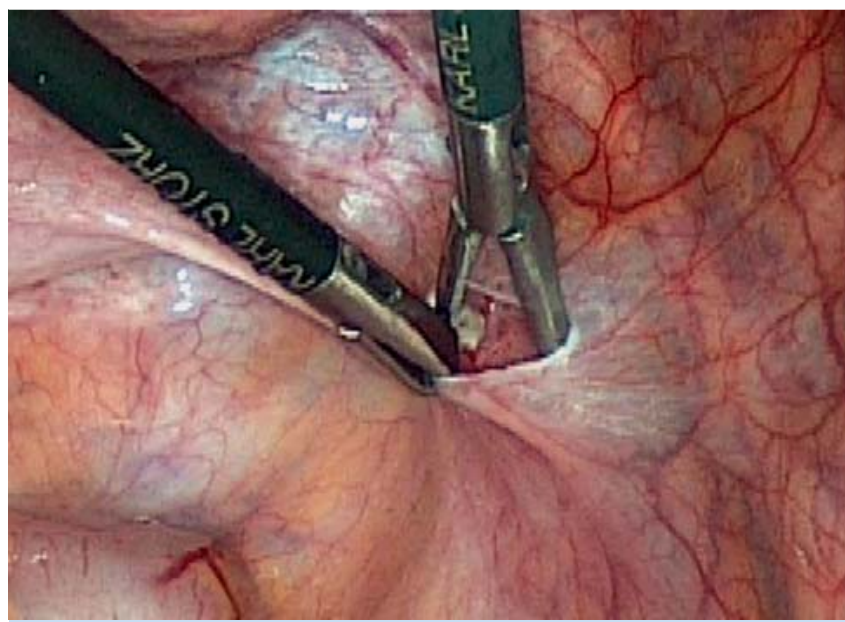

Fig. 4 Transplantation site of frozen-thawed ovarian tissue in the right pelvic wall.

[23]. In a review of their first 60 ovarian transplants, Donnez et al. described transplantation to the ovary consisting of initial preparation of the ovarian cortex (decortication) followed by microsurgical suturing of ovarian cortical pieces using $6-0$ or $7-0$ propylene sutures or, alternatively, fixing the graft on the medulla with Interceed or fibrin glue. If there was no functional ovarian tissue, Donnez et al. proposed incising the peritoneum at the anterior leaf of the broad ligament near a visible vascular network, placing the pieces in the peritoneal window, covering the graft with Interceed and fixing the edges with fibrin glue [11]. In their case report Sanchez-Serrano et al. also attached the peritoneal graft using fibrin glue and subsequently also used fibrin glue to close the peritoneum [13]. Dittrich et al. abstained from fixing the graft using any foreign material, did not close the peritoneum and did not carry out any coagulation. Three other centers which carried out ovarian grafting in 18 women recommended closing the peritoneum with sutures $[19,20,23]$.

Table 1 Surgical techniques used for ovarian tissue extraction reported in the literature.

\begin{tabular}{|c|c|c|}
\hline Investigated surgical criterion & Options & Articles \\
\hline \multirow[t]{3}{*}{ Surgical approach used for ovarian tissue extraction } & Laparotomy & {$[21,22]$} \\
\hline & Laparoscopy & {$[9-20]$} \\
\hline & Laparoscopy + laparotomy & No data \\
\hline \multirow[t]{4}{*}{ Amount of ovarian tissue extracted } & $3 / 3$ of an ovary & {$[15,17,18]$} \\
\hline & $\leq 2 / 3$ of an ovary & {$[9,11,21]$} \\
\hline & $\leq 1 / 3$ of an ovary & {$[12-14,19]$} \\
\hline & Ovarian biopsy $<2 \mathrm{~mm}$ & {$[10,16,22]$} \\
\hline \multirow[t]{3}{*}{ Instruments used during extraction } & Scissors or scalpel without coagulation & {$[9,11,20]$} \\
\hline & Scissors or scalpel with coagulation & No data \\
\hline & Biopsy forceps & {$[22]$} \\
\hline \multirow[t]{5}{*}{ Treatment of ovarian surface after extraction } & Hemostasis through coagulation & {$[21,22]$} \\
\hline & No coagulation & No data \\
\hline & Ovarian reconstruction using adaptive sutures & No data \\
\hline & No ovarian reconstruction & [9] \\
\hline & Application of fibrin glue to the excision surface & {$[22]$} \\
\hline \multirow[t]{2}{*}{ Simultaneous surgical procedures during extraction } & Myoma enucleation & [9] \\
\hline & Chromotubation & {$[20]$} \\
\hline
\end{tabular}


Table 2 Surgical techniques used for ovarian tissue transplantation reported in the literature.

\begin{tabular}{|lll}
\hline $\begin{array}{l}\text { Investigated surgical criterion } \\
\text { Surgical approach for ovarian tissue transplantation }\end{array}$ & Options & Articles \\
& Laparotomy & {$[12,24]$} \\
\hline & Laparoscopy & {$[9,10,13,16,17,19,22,25]$} \\
\hline Graft site & Laparoscopy + laparotomy & {$[18,21]$} \\
\hline & Peritoneal pocket in the pelvic wall near the ovary & {$[9,10,12,13,15-18,21,22,25]$} \\
\hline & Ipsilateral ovary & {$[9,15,18]$} \\
\hline & Contralateral ovary & {$[12,13]$} \\
\hline & Ipsilateral or contralateral ovary & {$[10,17,21,22,25]$} \\
\hline & Ipsilateral and contralateral ovary at the same time & {$[19,24]$} \\
\hline Instruments used during transplantation & Heterotopic transplantation into abdominal subcutaneous fat tissue & {$[15,17,21,25]$} \\
\hline & Scissors or scalpel without coagulation & {$[9]$} \\
\hline Surgical treatment of the transplant site & Biopsy forceps & {$[22]$} \\
\hline & No closure of the peritoneum after transplantation & {$[9]$} \\
\hline & Sutures used to close the peritoneum after transplantation & {$[10,12,18,19,22]$} \\
\hline & Fibrin glue used to close the peritoneum after transplantation & {$[10,12]$} \\
\hline Simultaneous surgical procedures performed & Fixation of the transplant using fibrin glue & {$[10,12]$} \\
\hline during transplantation & No coagulation of the peritoneum & {$[9]$} \\
\hline & Coagulation of the peritoneum & keine Daten \\
\hline
\end{tabular}

Surgical procedures carried out simultaneously during transplantation

There is little data available on simultaneous procedures. Dittrich et al. were the only group to report carrying out chromotubation during ovarian transplantation. Their standard procedure also included drain placement [10].

- Table 2 provides an overview of published surgical techniques used for the transplantation of ovarian tissue.

\section{Conclusion}

The extraction of ovarian tissue prior to commencing oncologic therapy and the subsequent re-implantation of this tissue after concluding cancer treatment is an innovative method which is becoming increasingly important in fertility surgery. A large number of centers have started to offer this procedure to affected women. The literature shows that the number of pregnancies and births following the transplantation of cryopreserved ovarian tissue has increased continually in recent years, indicating that this has become an established procedure. Nevertheless, data on the best surgical technique for this fertility-preserving method is limited. This review was compiled to at least partially close this knowledge gap.

The analysis of 17 articles on the extraction and/or transplantation of ovarian tissue showed that different centers use different surgical procedures. There was a broad consensus regarding the route used for surgical access. All centers favored a laparoscopic approach for extraction and transplantation. Mini-laparotomy, usually performed by a pediatric surgeon, was only used to treat children. A laparoscopic approach appears to be useful as the decision for ovarian cryopreservation is often taken when patients do not have much time before they need to start chemotherapy. The benefit of the laparoscopic approach is that patients are back on their feet very quickly following this minimally invasive procedure and can even be discharged on the day of surgery itself, allowing them to start chemotherapy without further delay. Lap- aroscopy is an integral part of surgical gynecology and is associated with a low rate of complications [27].

Opinion is more divided on the question of the amount of ovarian tissue to be extracted. Donnez et al. pointed out that biopsies of the ovarian cortex need to be at least $1 \mathrm{~mm}$ thick, otherwise they will not include primordial follicles under the mesothelium [10]. Other centers prefer ovarian sampling with sample sizes ranging from $1 / 3$ to $2 / 3$ of the ovary $[10,12-15,20,22]$ or even extraction of an entire ovary $[16,18,19]$. This approach is acceptable as follicle recruitment and hormone production after the loss of one ovary is maintained by the remaining ovary [28]. The sampling of a large piece of ovarian tissue offers the opportunity to potentially carry out repeat transplantations of different portions, which could help maintain reproductive and endocrine ovarian function for longer. A possible compromise between the different approaches of the centers could consist of removing a large part of one ovary prior to scheduled aggressive chemotherapy (e.g. highdose chemotherapy and whole-body irradiation prior to bone marrow transplant, chemotherapy with alkylating agents) but leaving more ovarian tissue in situ when protocols are less toxic. The preferred instruments used in most centers both for tissue extraction and transplantation were scissors or scalpel without coagulation. Silber et al. reported using bipolar biopsy forceps for hemostasis [23]. Rosendahl et al. have pointed out that coagulation can damage ovarian tissue and reduce ovarian reserve by decreasing the number of primary follicles [22]. Great care must be taken when applying electrical current intraoperatively and current should not be applied to or near the resected tissue. Opinions on the proper treatment of the ovarian surface also differ between centers. Options include bipolar coagulation or treatment of the area with sutures and fibrin glue but also abstaining from coagulation. The benefits of preserving ovarian tissue need to be weighed against the potential risk of secondary hemorrhage.

There are 3 potential sites for transplantation: transplantation to the ipsilateral and/or contralateral ovary, into an ipsilateral and/ or contralateral peritoneal pocket, and heterologous transplantation. Potential benefits of the ovary as the site of re-transplanta- 
tion are that the tissue was originally taken from the same site and the transplanted sample can be located easily and removed if necessary. However, the risk of bleeding is higher and there is also a potential risk of trauma to the ovary which can be avoided by transplantation into a peritoneal pocket. The advantage of heterotopic transplantation is that abdominal surgery is not required. On the other hand, all births published to date occurred following orthotopic transplantation [11]. Moreover, heterotopic transplantation requires aspiration of the oocyte from the sampled ovary followed by in vitro fertilization, whereas spontaneous pregnancy has been reported to occur following orthotopic transplantation. Treatment of the transplantation site during surgery is also controversial. While most centers fixed the transplanted ovarian cortex either to the ovary or the peritoneum with sutures or fibrin glue, one center [10] suggested not treating the transplanted tissue $[10,11,13]$. If cortical tissue is transplanted into the peritoneum, the option is either to close the peritoneum with sutures or to aim for spontaneous adaptation. The advantages of suturing is the secure closure of the created pocket which ensures that the transplanted tissue will not fall out. One of the disadvantages of closing the peritoneum with sutures or other materials is the associated additional trauma to surrounding tissue and the potentially higher risk of adhesions and postoperative pain. The introduction of foreign materials such as sutures or glue can trigger foreign body granulomas and potentially lead to rejection of the transplanted tissue. It should be noted that the Misgav Ladach method for cesarean section also does not close the peritoneum.

The final point investigated in this review was whether other surgical procedures were carried out simultaneously during the extraction or transplantation of ovarian tissue. Only 2 working groups reported carrying out simultaneous procedures $[10,20]$. It would make sense to remove myomas or deal with other potential fertility-reducing factors and to test for tubal patency during the re-implantation of ovarian tissue. There are a number of reports of spontaneous conception after the transplantation of ovarian tissue [20]. It is possible that other centers also carried out chromotubation without mentioning it in their articles. This is one of the limitations of this literature review. The data are very limited. Many articles only give a very broad description of the surgical technique employed. Some authors wrote that they used the "standard procedure", although no "standard procedure" has yet been defined.

In summary, a review of the literature on the surgical techniques used for the extraction and transplantation of ovarian tissue has shown that a number of different surgical techniques are currently in use for this fertility-preserving method. Because of the small numbers of cases treated in the respective centers and the many variations in technique, it is not clear which surgical technique is best. One of the future tasks will be to develop a standard surgical technique which will be both highly practicable and extremely functional with a functioning transplantation site and high pregnancy and birth rates.

\section{Conflict of Interest}

$\nabla$

The authors declare they have no conflict of interest.

\section{References}

1 Mattle $V$, Behringer $K$, Engert $A$ et al. Female fertility after cytotoxic therapy-protection of ovarian function during chemotherapy of malignant and non-malignant diseases. Eur J Haematol Suppl 2005; 66: 7782

2 Anderson RA, Wallace WH, Baird DT. Ovarian cryopreservation for fertility preservation: indications and outcomes. Reproduction 2008; 136: 681-689

3 Lee MC, Gray J, Han HS et al. Fertility and reproductive considerations in premenopausal patients with breast cancer. Cancer Control 2010; 17: $162-172$

4 Ethics Committee of American Society for Reproductive Medicine. Fertility preservation and reproduction in patients facing gonadotoxic therapies: a committee opinion. Fertil Steril 2013; 100: 1224-1231

5 Anderson R, Adamson D, Yellowlees A et al. GnRH agonist for protection against ovarian toxicity during chemotherapy for early breast cancer: the OPTION trial. Anglo Celtic Collaborative Oncology Group and NCRI trialists P 488, ESHRE, Helsinki, 2016, Abstractbook i339

6 Shou $H$, Chen $Y$, Chen $Z$ et al. Laparoscopic ovarian transposition in young women with cervical squamous cell carcinoma treated by primary pelvic irradiation. Eur J Gynaecol Oncol 2015; 36: 25-29

7 Bénard J, Duros S, Hachem HE et al. Freezing oocytes or embryos after controlled ovarian hyperstimulation in cancer patients: the state of the art. Future Onco 2016; DOI: 10.2217/fon-2016-0095

8 Findeklee S, Lotz L, Heusinger $K$ et al. Fertility protection in female oncology patients: how should patients be counseled? Geburtsh Frauenheilk 2015; 75: 1243-1249

9 Donnez J, Silber S, Andersen CY et al. Children born after autotransplantation of cryopreserved ovarian tissue: a review of 13 live births. Ann Med 2011; 43: 437-450

10 Dittrich R, Hackl J, Lotz L et al. Pregnancies and live births after 20 transplantations of cryopreserved ovarian tissue in a single center. Fertil Steril 2015; 103: 462-468

11 Donnez J, Dolmans MM, Pellicer A et al. Restoration of ovarian activity and pregnancy after transplantation of cryopreserved ovarian tissue: a review of 60 cases of reimplantation. Fertil Steril 2013; 99: 15031513

12 Huober-Zeeb C, Lawrenz B, Popovici RM et al. Improving fertility preservation in cancer: ovarian tissue cryobanking followed by ovarian stimulation can be efficiently combined. Fertil Steril 2011; 95: 342-344

13 Sanchez-Serrano $M$, Crespo J, Mirabet $V$ et al. Twins born after transplantation of ovarian cortical tissue and oocyte vitrification. Fertil Steril 2010; 93: 268.e11-268.e13

14 Sanchez M, Novella-Maestre E, Teruel J et al. The Valencia Programme for Fertility Preservation. Clin Transl Oncol 2008; 10: 433-438

15 Rosendahl M, Andersen CY, Ernst $E$ et al. Ovarian function after removal of an entire ovary for cryopreservation of pieces of cortex prior to gonadotoxic treatment: a follow-up study. Hum Reprod 2008; 23: 24752483

16 Schmidt KL, Andersen CY, Loft A et al. Follow-up of ovarian function post-chemotherapy following ovarian cryopreservation and transplantation. Hum Reprod 2005; 20: 3539-3546

17 Donnez J, Dolmans MM, Demylle D et al. Livebirth after orthotopic transplantation of cryopreserved ovarian tissue. Lancet 2004; 364: 1405-1410

18 Demeestere I, Simon P, Emiliani S et al. Fertility preservation: successful transplantation of cryopreserved ovarian tissue in a young patient previously treated for Hodgkin's disease. Oncologist 2007; 12: 1437-1442

19 Revel A, Laufer N, Ben Meir A et al. Micro-organ ovarian transplantation enables pregnancy: a case report. Hum Reprod 2011; 26: 1097-1103

20 Revelli A, Marchino G, Dolfin E et al. Live birth after orthotopic grafting of autologous cryopreserved ovarian tissue and spontaneous conception in Italy. Fertil Steril 2013; 99: 227-230

21 Lawrenz B, Jauckus J, Kupka MS et al. Fertility preservation in >1,000 patients: patient's characteristics, spectrum, efficacy and risks of applied preservation techniques. Arch Gynecol Obstet 2011; 283: 651656

22 Rosendahl M, Schmidt KT, Ernst E et al. Cryopreservation of ovarian tissue for a decade in Denmark: a view of the technique. Reprod Biomed Online 2011; 22: 162-171

23 Silber S, Kagawa N, Kuwayama M et al. Duration of fertility after fresh and frozen ovary transplantation. Fertil Steril 2010; 94: 2191-2196

24 Dolmans MM, Jadoul P, Gilliaux $S$ et al. A review of 15 years of ovarian tissue bank activities. J Assist Reprod Genet 2013; 30: 305-314 
25 Meirow D, Levron J, Eldar-Geva T et al. Pregnancy after transplantation of cryopreserved ovarian tissue in a patient with ovarian failure after chemotherapy. N Engl J Med 2005; 353: 318-321

26 Imbert R, Moffa F, Tsepelidis $S$ et al. Safety and usefulness of cryopreservation of ovarian tissue to preserve fertility: a 12-year retrospective analysis. Hum Reprod 2014; 29: 1931-1940
27 Krishnakumar S, Tambe P. Entry complications in laparoscopic surgery. J Gynecol Endosc Surg 2009; 1: 4-11

28 Khan Z, Gada RP, Tabbaa ZM et al. Unilateral oophorectomy results in compensatory follicular recruitment in the remaining ovary at time of ovarian stimulation for in vitro fertilization. Fertil Steril 2014; 101: $722-727$ 